\title{
Erratum: Changes in Gene Expression Pattern of Human Primary Macrophages Induced by Carbosilane Dendrimer 2G-NN 16
}

Rafael Gras • Luis Almonacid • Paula Ortega • Maria J. Serramia • Rafael Gomez • F. Javier de la Mata $\bullet$ Luis A. Lopez-Fernandez • M. Angeles Muñoz-Fernandez

Published online: 30 November 2010

(C) Springer Science+Business Media, LLC 2010

\section{Erratum to: Pharm Res \\ DOI 10.1007/s11095-010-0328-y}

\section{ERRORS}

- The "Materials and Methods" section stated, "Control and dendrimer probes were labeled, respectively, with Alexa Fluor 647 reactive dye decapack and Alexa Fluor 555 reactive dye decapack." This section should state, "Control and dendrimer probes were labeled, respectively, with Alexa Fluor 555 reactive dye decapack and Alexa Fluor 647 reactive dye decapack."

- There was a mistake in the microarray quantification files, and a new analysis has been done. The new microarray data have been corrected in Gene Expression Omnibus (Series accession number GSE12405). As a consequence of this mistake, Figure 3, Figure 4, Table I, Table II and Supplemental Table have been changed as follows. In spite of this error, conclusions remain valid.

The online version of the original article can be found at doi: 10. $1007 /$ sl 1095-008-9776-z.

Electronic Supplementary Material The online version of this article (doi: | 0. I 007/s | |095-0 I0-0328-y) contains supplementary material,

which is available to authorized users.

R. Gras $\cdot$ L. A. Lopez-Fernandez $(\varangle)$

Laboratory of Pharmacogenetics and Pharmacogenomics

Hospital General Universitario Gregorio Marañon

28007, Madrid, Spain

e-mail: llopezf.hgugm@salud.madrid.org

R. Gras • M. J. Serramia $\cdot$ L. A. Lopez-Fernandez •

M. A. Muñoz-Fernandez

Laboratory of Molecular Immunobiology

Hospital General Universitario Gregrorio Marañon

28007, Madrid, Spain

\section{CHANGES AND IMPLICATIONS}

Change: The number of genes over-expressed or underrepressed more than twice is 2,706 and 5,560 genes for Dendrimer (DM) and Dendriplex (DX), respectively.

Implication: This change has no effect on discussion, and it is not relevant because the analysis is performed on a selection of these genes.

Change: The number of genes differentially expressed, applying filtering by p-value $(<0.05)$, average signal $(>32)$ and $z$-score $(>1.8$ or $<-1.8)$, are 141 and 215 for DM and DX exposure, respectively.

Implication: A number of selected genes by dendrimer or dendriplex exposure is now more homogeneous.

\author{
L. Almonacid \\ National Center for Biotechnology \\ 28049, Madrid, Spain \\ P. Ortega • R. Gomez • F. J. de la Mata \\ Departamento de Quimica Inorganica Universidad de Alcala \\ Campus Universitario \\ 2887I, Alcala de Henares, Spain
}

P. Ortega $\cdot$ M. J. Serramia $\cdot$ R. Gomez • F. J. de la Mata •

M. A. Muñoz-Fernandez

Networking Research Center on Bioengineering, Biomaterials and

Nanomedicine (CIBER-BBN)

Barcelona, Spain 

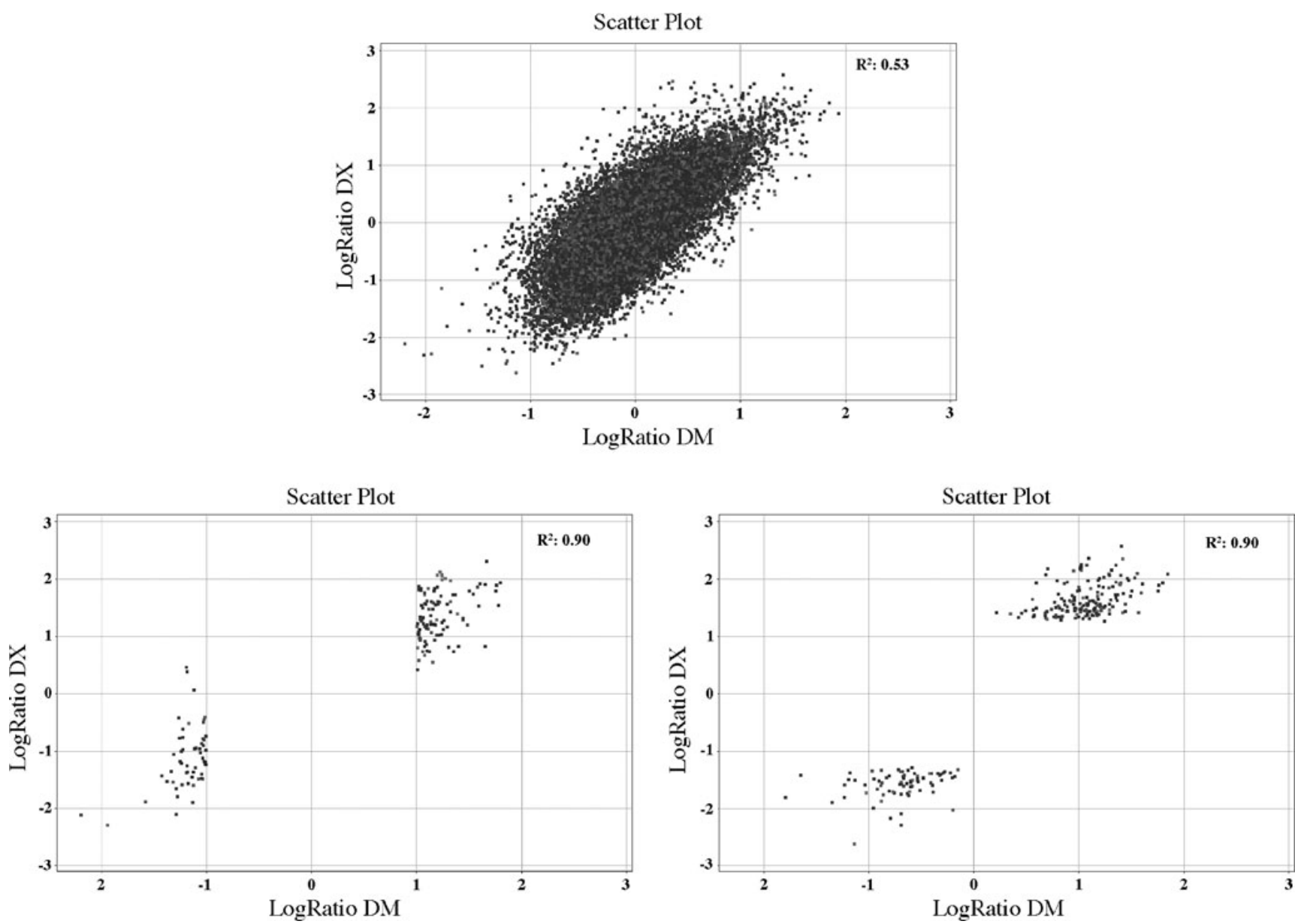

Fig. 3 (top) LogRatio Scatter Plot of macrophages exposed to $5 \mu$ M 2G-NNI6 versus Dendriplex. Spots were filtered by Average intensity higher than 32 units in both conditions. Correlation factor (R2) was 0,53, indicating a high level of correlation. (bottom left) Scatter plot (dendrimer vs dendriplex) with significant selected genes differentially expressed in response to dendrimer exposure. (bottom right) Scatter plot (dendrimer vs dendriplex) of significant genes differentially expressed in response to dendriplex exposure. High correlations $(R 2=0.90)$ are observed.

Change: The correlation, measured by a logistic regression, between DM and DX microarray data of all genes with an average signal higher than 2 is 0.53 . The correlation for the $141 \mathrm{DM}$ selected genes with the corresponding values in DX arrays was 0.90. The correlation for the $214 \mathrm{DX}$ selected genes with the corresponding values in DM arrays was 0.90 .

Implication: The correlation between DM and DX data for genes with an average signal higher than 32 is lower than in our previous publication. However, the most important correlation, concerning genes selected for the functional analysis, still has a high significance $\left(\mathrm{R}^{2}=0.90\right)$. Therefore, the assumption published in our manuscript that dendrimer alone has basically the same effect on gene expression as dendriplex is also valid for the new data.

Change: The unique list with the most significant differentially expressed genes in DM and/or DX exposed now macrophages now includes 336 different genes, instead of 331 .

Implication: Obviously, both the lists of selected genes regulated by DM and DX exposure and their corresponding values of Fold Change and p-Value have been modified. However, the most regulated genes published in our manuscript are still selected, principally IL17F, which plays an important role in the discussion and conclusions of our manuscript. RT-PCR of IL17F, IL23R and IL23A are not affected by the new microarray analysis.

Change: The five principal processes identified by Ingenuity with the new list of genes are summarised in the new Table II. "Cellular movement" remains as the highest scored category $\left(\mathrm{p}=4.07 \times 10^{-7}\right)$, but the rest of them are not in the new top five of the list. Therefore, the rest of the categories published in the previous manuscript are still 


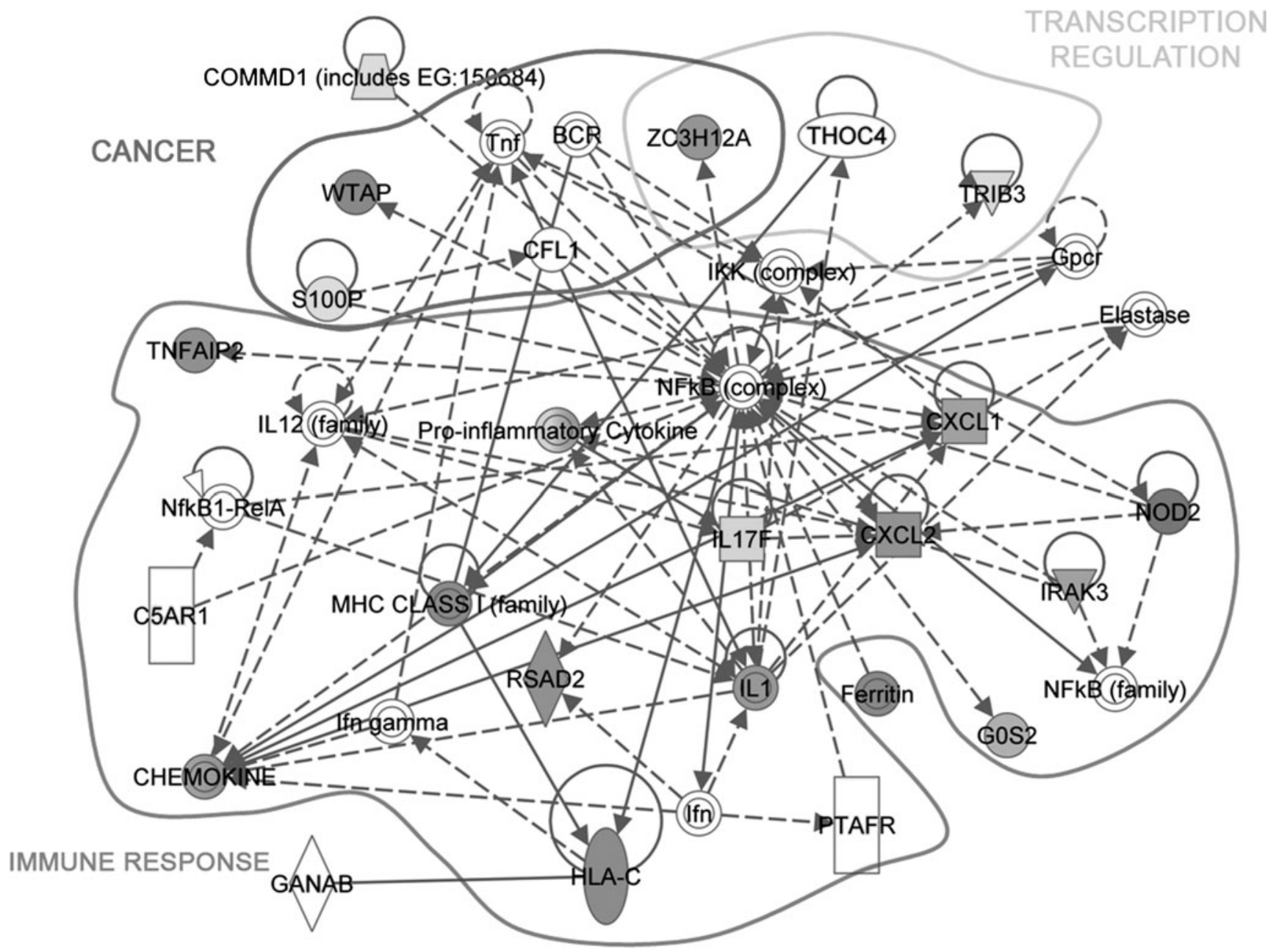

Fig. 4 Graphical representation of Network I introducing the list of selected genes in Ingenuity Pathways Analysis. Three principal functions are observed: immune system, cancer and transcriptional regulation.

statistically significant ("Hematological development and function": $p=3.1 \times 10^{-5}$, "Cell-to-cell signaling and interaction": $p=9.96 \times 10^{-3}$, "Immune response: $p=9.96 \times 10^{-3}$ ", "Inflammatory disease": $\mathrm{p}=8.07 \times 10^{-3}$, "Connective tissue disorders": $\left.p=6.12 \times 10^{-3}\right)$. It is important to underline that Ingenuity is a dynamic database that continuously incorporates new relations and functions for the different genes.

Implication: The Ingenuity analysis of the principal processes affected reveals that the previously published processes are also significantly affected in the new analysis. However, new processes appear now with a higher score as a consequence of the new list of genes. Basically, cell death, cellular development and proliferation appear now. These categories are closely related, and many of the genes involved are common. In our manuscript we said previously that proliferation was one of the most affected functions by
DM/DX exposure in macrophages based on the most significant network found by Ingenuity analysis. Thus, it confirms the previous published conclusions. To test the reproducibility of the data, we analysed the same list of genes of the incorrect microarray data published. Results shown different top-five categories based on the statistical significance. Therefore, in general, results of Ingenuity must be taken with caution.

Change: Immune response, principally, and cancer remain to be over-represented in the most significant network identified by Ingenuity Pathway analysis.

Implication: The most significant gene network found by Ingenuity using the new gene list shows that immune response, cancer and transcription regulation are highly represented. This result is very similar to previously published, in spite of some changes in genes in both old and new list. 
Table I List of the 50 Most

Regulated Genes in Macrophages by NNI 6 and Dendriplex Exposition

\begin{tabular}{|c|c|c|c|c|}
\hline Symbol & Fold Change DM & $p$-value DM & Fold Change DX & $p$-value DX \\
\hline ILI7F & -4.59 & 0.0180 & -4.31 & 0.0608 \\
\hline $\mathrm{EFHB}$ & -3.86 & 0.0443 & -4.89 & 0.1250 \\
\hline TEX26। & -3.48 & 0.0755 & -3.48 & 0.0357 \\
\hline FUT7 & -3.15 & 0.1849 & -2.67 & 0.0224 \\
\hline A_24_PI70309 & -3.01 & 0.0200 & -3.68 & 0.0659 \\
\hline$\times 58329$ & -2.70 & 0.0069 & -2.68 & 0.0745 \\
\hline A_24_P2I2605 & -2.60 & 0.0116 & -2.88 & 0.0841 \\
\hline TRIB3 & -2.56 & 0.2185 & -3.70 & 0.0276 \\
\hline LOC44I 238 & -2.53 & 0.0017 & -2.54 & 0.0882 \\
\hline CXCR6 & -2.50 & 0.0265 & -2.90 & 0.1773 \\
\hline PTPLAD2 & -2.49 & 0.0079 & -2.08 & 0.1983 \\
\hline LRRN3 & -2.45 & 0.0254 & -4.30 & 0.0965 \\
\hline LOC44I893 & -2.45 & 0.0139 & -3.14 & 0.2581 \\
\hline D31828 & -2.42 & 0.0125 & -3.45 & 0.1973 \\
\hline C9orfl I9 & -2.41 & 0.0128 & -1.33 & 0.1766 \\
\hline A_24_P8849I5 & -2.40 & 0.0166 & -1.70 & 0.0497 \\
\hline A_24_P233560 & -2.38 & 0.0120 & -2.27 & 0.1361 \\
\hline CSTF3 & -2.37 & 0.0455 & -2.31 & 0.0402 \\
\hline RPSIO & -2.36 & 0.0392 & -2.00 & 0.0782 \\
\hline ZMAT5 & -2.36 & 0.0216 & -3.00 & 0.0398 \\
\hline HPGD & -2.35 & 0.1171 & -3.49 & 0.0217 \\
\hline LOC39222I & -2.35 & 0.0309 & -1.69 & 0.0027 \\
\hline ANKRD2 & -2.35 & 0.0285 & -1.53 & 0.4301 \\
\hline MGCI7330 & -2.35 & 0.1701 & -3.01 & 0.0420 \\
\hline SEDLP & -2.34 & 0.0490 & -1.96 & 0.0393 \\
\hline STAM2 & 2.68 & 0.1513 & 2.67 & 0.0489 \\
\hline AK094950 & 2.68 & 0.1714 & 5.12 & 0.0156 \\
\hline AK000420 & 2.69 & 0.0618 & 3.37 & 0.0441 \\
\hline MICALCL & 2.71 & 0.0247 & 2.50 & 0.0214 \\
\hline ANKRDI 2 & 2.72 & 0.1705 & 2.96 & 0.0379 \\
\hline BTN2A2 & 2.72 & 0.0658 & 2.72 & 0.0035 \\
\hline PDE4DIP & 2.72 & 0.0451 & 2.44 & 0.0386 \\
\hline A_23_PI36849 & 2.80 & 0.0478 & 2.29 & $0.047 \mid$ \\
\hline THC2694735 & 2.81 & 0.2077 & 3.27 & 0.0245 \\
\hline THC2623234 & 2.83 & 0.0379 & 3.45 & 0.0388 \\
\hline THC27I 9547 & 2.90 & 0.0381 & 3.33 & 0.0503 \\
\hline A_23_PI360I3 & 2.95 & 0.0748 & 4.28 & 0.0461 \\
\hline ZFYVI6 & 2.97 & 0.0807 & 2.66 & 0.0487 \\
\hline THC255965I & 2.99 & 0.0289 & 3.63 & 0.1231 \\
\hline NBPFI 5 & 3.01 & 0.0789 & 3.39 & 0.0193 \\
\hline FLJII I 292 & 3.02 & 0.0489 & 2.89 & 0.0812 \\
\hline STRN3 & 3.04 & 0.0348 & 3.77 & 0.0338 \\
\hline NOD2 & 3.14 & 0.0452 & 3.73 & 0.0643 \\
\hline COXI & 3.15 & 0.0214 & 1.77 & 0.3774 \\
\hline NBPFII & 3.17 & 0.0141 & 4.96 & 0.0648 \\
\hline THC2476I26 & 3.37 & 0.0444 & 3.46 & 0.0083 \\
\hline AB040974 & 3.38 & 0.0290 & 3.70 & 0.0016 \\
\hline BTN2AI & 3.44 & 0.0225 & 2.90 & 0.0596 \\
\hline THC2545558 & 3.47 & 0.0255 & 3.81 & 0.0184 \\
\hline USP54 & 3.59 & 0.0844 & 4.26 & 0.0447 \\
\hline
\end{tabular}


Table II Results of Analysis using the Ingenuity Pathway Analysis SoftwareShowing the Functions with the Highest Probability to be Affected in Macrophages by Dendrimer/Dendriplex Exposure

\begin{tabular}{|c|c|c|c|}
\hline Category & Function Annotation & Significance & Molecules \\
\hline Cellular Movement & $\begin{array}{l}\text { movement of } \\
\text { eukaryotic cells }\end{array}$ & 0 & $\begin{array}{l}\text { APBBI, ARHGAP24, BAX, C5ARI, CCDC88A, CFLI, CKLF, CXCLI, } \\
\text { CXCL2, DOCK4, EBFI, EREG, FUT7, HBEGF, HIFIA, HOXB2, IL7, ILIB } \\
\text { ITGB2, LYST, MAPK3, MARCKS (includes EG:4082), MET, MXDI, NFKBIA } \\
\text { PDLIM2, PIMI, PLDI, PPARG, SI OOP, SDCBP, SERPINB2, SHCI, SLCIA2 } \\
\text { SOD2, SPII, VEGFA, WNT5A, ZEB2 }\end{array}$ \\
\hline Cell Death & cell viability of cell lines & 0 & $\begin{array}{l}\text { BAX, CD7, CLN3, FTHI, IL7, ILIB, MET, NFAT5, NFKBIA, OGGI, SHCI } \\
\text { SOD2, VEGFA }\end{array}$ \\
\hline Cellular Development & $\begin{array}{l}\text { developmental process } \\
\text { of fibroblast cell lines }\end{array}$ & 0 & $\begin{array}{l}\text { CCND3, DYRKIA, EBFI, EREG, HBEGF, ILIB, MET, MLLT6, MXDI, } \\
\text { NFKBIA, PPARG, RASGRP4, RBI, SHCI, TRIB3, WNT5A }\end{array}$ \\
\hline $\begin{array}{l}\text { Cellular Growth and } \\
\text { Proliferation }\end{array}$ & growth of cell lines & 0 & $\begin{array}{l}\text { BAX, CCND3, CLN3, CXCLI, CXCL2, EIF5A, ELOVL7, EREG, FTHI, } \\
\text { HBEGF, HIFIA, HPGD, IL7, ILIB, KIFI3A, MAPK3, MET, MLLT6, NFKBIA } \\
\text { PIMI, PPARG, RASGRP4, RBI, RPS6KBI, SATI, SGMSI, SOD2, SPII, } \\
\text { VEGFA, WNT5A, ZMYM2 }\end{array}$ \\
\hline $\begin{array}{l}\text { Skeletal and Muscular System } \\
\text { Development and Function }\end{array}$ & $\begin{array}{l}\text { skeletal and muscular } \\
\text { process of cell lines }\end{array}$ & 0 & ILIB, MET, NFKBIA, PLDI, PPARG, RPS6KBI, SHCI \\
\hline
\end{tabular}

Selected genes were included in Ingenuity to have this result. In the table, parameters such as Category, Function Annotation, Significance and Molecules are presented. 